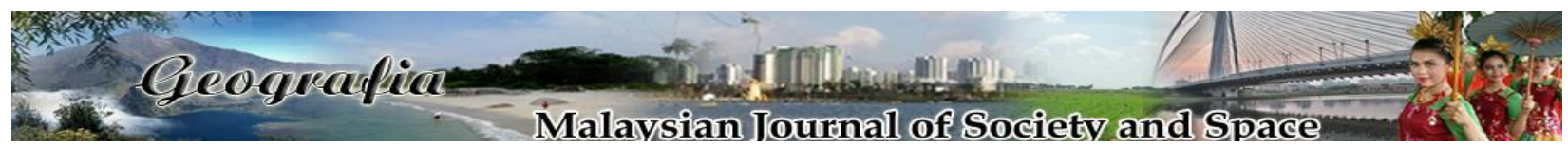

\title{
Penerokaan kefungsian keluarga dalam kalangan banduan muda lelaki Malaysia: Satu kajian kualitatif
}

\author{
Mohammad Rahim Kamaluddin ${ }^{1}$, Noor Nasiha Kamarudin ${ }^{1}$, Siti Nurkhairina Mohd Nor ${ }^{1}$, \\ Kausalya Devi Sathoo' ${ }^{2}$, Saravanan Meyappan ${ }^{3}$, Nadzriah Ahmad ${ }^{4}$ \\ ${ }^{1}$ Pusat Kajian Psikologi dan Kesejahteraan Manusia, Fakulti Sains Sosial dan Kemanusiaan, \\ Universiti Kebangsaan Malaysia \\ ${ }^{2}$ Jabatan Penjara Malaysia, Malaysia \\ ${ }^{3}$ Mahkamah Kuala Lumpur, Malaysia \\ ${ }^{4}$ Fakulti Undang-Undang, Universiti Teknologi Mara (UiTM), Shah Alam, Selangor, Malaysia \\ Correspondence: Mohammad Rahim Kamaluddin (rahimk@ukm.edu.my)
}

Received: 20 November 2020; Accepted: 07 March 2021; Published: 29 May 2021

\begin{abstract}
Abstrak
Penglibatan banduan muda lelaki dalam jenayah dan tingkah laku delinkuen telah mencetuskan permasalahan sosial dalam masyarakat Malaysia pada hari ini. Namun begitu, kajian berkaitan penglibatan banduan muda lelaki dalam jenayah dari perspektif faktor kefungsiaan keluarga masih kurang diberikan penekanan dan memerlukan penelitian lanjut. Sehubungan itu, kajian ini dilakukan bertujuan untuk meneroka aspek kefungsian keluarga yang membawa kepada tingkah laku jenayah dalam kalangan banduan muda lelaki di salah sebuah Sekolah Integriti di Malaysia. Kajian ini menggunakan teknik temu bual mendalam di mana seramai 12 orang banduan muda lelaki telah ditemu bual. Kaedah penyelidikan kualitatif dan pemerhatian secara langsung telah digunakan bagi mengutip data di dalam kajian ini. Peserta kajian dipilih berdasarkan persampelan pemilihan berkriteria dan transkrip temu bual dianalisis dengan menggunakan kaedah tematik. Hasil kajian mendapati empat tema berkaitan kefungsiaan keluarga iaitu kekurangan kasih sayang, keluarga bermasalah, dendam terhadap ahli keluarga dan keterlibatan ahli keluarga dalam jenayah. Hasil dapatan kajian ini boleh dijadikan sebagai garis panduan untuk membangunkan modul-modul di sekolah untuk mengelak remaja dan pelajar sekolah daripada terlibat dengan jenayah dan tingkah laku delinkuen. Selain itu, kajian ini juga menjadi manfaat bagi institusi kekeluargaan dan masyarakat dalam memahami faktor-faktor penyebab tingkah laku delinkuen dalam kalangan remaja dengan lebih mendalam.
\end{abstract}

Kata kunci: Banduan muda lelaki, jenayah, kefungsiaan keluarga, tingkah laku delinkuen 


\title{
Exploring familial function among Malaysian young male prisoners: A qualitative study
}

\begin{abstract}
The involvement of incarcerated young males in crimes and delinquency has sparked social issues in present Malaysian society. However, studies related to involvement of young male offenders from the perspective of familial function are underexplored and warrant further attention. The present qualitative research, therefore, was undertaken to explore the familial function that has influence on delinquency and criminal behaviour among young male prisoners from Henry Gurney School in Malaysia. Twelve participants were selected using the purposive sampling technique. In-depth interviews were conducted to explore the familial function of young male prisoners. The informants were selected based on several selection criteria and data were analysed using the thematic approach. From the analyses, four prominent themes emerged such as lack of love, problematic family, revenge towards family members and involvement of family members in crime. The findings of this study may serve as guidance for future researchers and authorities to develop modules in schools that can help prevent schooling teenagers from being involved in various types of crime and delinquent behaviours. Additionally they may be significant in offering in-depth understanding about salient factors of delinquency for members of familial institutions and societies.
\end{abstract}

Keywords: Young male prisoners, crime, familial function, delinquent behaviour

\section{Pengenalan}

Golongan muda merupakan pewaris kepada kepimpinan, pembangunan dan kesejahteraan sesebuah negara. Oleh itu, golongan muda perlu dipastikan agar mereka cemerlang dalam pelbagai aspek seperti akademik, kemahiran, sahsiah dan lain-lain kualiti diri yang diperlukan untuk menyambung tugas dan tanggung jawab sebagai pewaris dan bakal pemimpin negara. Walau bagaimanapun, usaha ini bukan suatu perkara yang mudah kerana perkembangan dunia tanpa sempadan menjanjikan pelbagai cabaran dan tekanan yang lebih hebat untuk golongan muda ini. Antara cabaran getir yang boleh membantutkan usaha menyediakan pewaris ini ialah masalah sosial, jenayah dan tingkah laku delinkuen dalam kalangan generasi muda atau remaja.

Secara amnya, konsep delinkuensi merujuk kepada tingkah laku jenayah membabitkan orang muda, remaja atau kanak-kanak yang bertentangan dengan ketetapan perundangan sesebuah negara (Regoli, Hewitt \& Delisi, 2008). Tingkah laku ini dikenali sebagai jenayah sekiranya dilakukan oleh orang dewasa. Tingkah laku delinkuen atau kesalahan jenayah yang serius dilakukan oleh seseorang boleh mengakibatkan mereka dikenakan hukuman undang-undang di mana di Malaysia pelaksanaan hukuman tersebut dilaksanakan oleh Jabatan Penjara Malaysia. Pesalah-pesalah terbabit akan ditempatkan di institusi-institusi penjara berdasarkan perintah atau waran yang dikeluarkan oleh pihak mahkamah atau pihak berkuasa lain yang kompetan.

Sepanjang tempoh penahanan dalam institusi penjara, pesalah akan menjalani program pemulihan yang dikenali sebagai Program Pembangunan Insan (PPI). PPI merupakan program yang dirangka khusus untuk mempertingkatkan pengetahuan, sikap dan kemahiran pesalah 
(Jabatan Penjara Malaysia, 2014). Program ini dibangunkan berasaskan perkembangan secara holistik seseorang individu berdasarkan perkembangan secara fizikal, sosial, mental dan kerohanian. Pemulihan yang dilaksanakan oleh Jabatan Penjara Malaysia dengan harapan dan matlamat agar mereka insaf akan kesilapan yang telah dilakukan dan berubah menjadi warganegara yang berguna, boleh meneruskan kehidupan dengan baik dan menyumbang kepada pembangunan keluarga, masyarakat dan negara. Apatah lagi jika pesalah yang disabitkan itu melibatkan golongan remaja, program pemulihan yang dilaksanakan mestilah berpandukan kefahaman yang tepat tentang aspek manakah yang boleh diberi perhatian untuk membantu mereka menyedari kesilapan dan bangkit semula menjadi manusia berguna serta tidak lagi mengulangi kesilapan lalu.

Sehingga September 2018, jumlah banduan muda (bawah 21 tahun) yang ditahan di institusi penjara biasa menghampiri jumlah 3,772 orang. Jumlah ini mewakili 5.9 peratus daripada jumlah keseluruhan banduan yang sedang ditahan di seluruh institusi penjara biasa. Sehingga September 2018 juga, lebih daripada 40 orang remaja (bawah 21 tahun) ditahan di Pusat Pemulihan Akhlak Jabatan Penjara. Manakala sehingga tarikh yang sama juga, jumlah remaja (Akta KanakKanak, 2001) yang ditahan di Institusi Sekolah Henry Gurney, Jabatan Penjara Malaysia menghampiri 1,352 orang. Jika dijumlahkan semua banduan muda, tahanan muda dan juvana yang berada di institusi penjara biasa, Pusat Pemulihan Akhlak dan Sekolah Henry Gurney maka jumlahnya mewakili sebanyak 8.2 peratus daripada jumlah banduan yang berada di keseluruhan institusi penjara di Malaysia.

Banyak faktor yang perlu difahami bagi menjelaskan mengapa banduan muda ini melakukan kesalahan jenayah dan delinkuensi. Salah satu aspek yang dikenal pasti ialah aspek kefungsiaan kekeluargaan dalam kehidupan mereka. Antara faktor yang dikenal pasti ialah aspek kefungsian kekeluargaan, pengaruh rakan sebaya dan elemen psikososial (Pereira \& Maia, 2017). McWhirter et al. (2013) dalam membincangkan masalah golongan belia berisiko turut menjelaskan bahawa tingkah laku delinkuen disumbangkan oleh faktor persekitaran sosial, keluarga dan ciriciri individu belia berisiko itu sendiri. Faktor risiko ini diterokai dengan tujuan untuk memahami sumbangannya kepada tingkah laku delinkuen yang boleh memberikan kefahaman mengapa banduan muda ini melakukan kesalahan jenayah. Ini sekaligus dapat dijadikan panduan untuk membangunkan modul-modul di sekolah bagi mengelak remaja atau pelajar sekolah terlibat dengan jenayah dan tingkah laku delinkuen.

Aspek kekeluargaan dilihat memainkan peranan penting dalam membentuk tingkah laku anti-sosial dan pro-jenayah; dan ianya bermula daripada rumah. Ini kerana setiap individu itu berasal daripada sebuah keluarga. Apabila seseorang anak itu dilahirkan, ibu bapa perlu menjaga dan mendidik anak tersebut dari rumah sehingga mereka mencapai suatu tahap kedewasaan dan kematangan untuk menerajui kehidupan mereka sendiri. Proses ini bukan hanya melibatkan jagaan fizikal tetapi juga perlu memastikan aspek psikososial anak itu berkembang dengan baik dan positif. Kanak-kanak dan remaja yang belum mencapai tahap kedewasaan serta kematangan sepenuhnya ini memerlukan keluarga untuk berhadapan dengan tekanan dan cabaran yang dilalui dalam kehidupan mereka seharian. Jika aspek kekeluargaan gagal diberikan dengan baik disebabkan oleh pelbagai faktor seperti ibu bapa bermasalah, penceraian, kematian dan sebagainya, maka risiko yang dihadapi ialah perkembangan remaja tidak berlaku dengan baik dan membuat keputusan untuk bertingkah laku delinkuen.

Masalah kepincangan kefungsian keluarga merupakan faktor yang paling asas mempengaruhi perkembangan remaja. Proses sosialisasi dan pembentukan personaliti remaja tidak dapat disempurnakan dengan baik jika sikap, nilai dan sistem kepercayaan positif gagal diterapkan 
dalam minda mereka akibat kegagalan fungsi keluarga. Keluarga gagal berfungsi dengan baik akibat keluarga bermasalah (problematic families) dan masalah keluarga (family problems). Antara isu-isu yang berkaitan ialah seperti keluarga terlibat penyalahgunaan bahan, penahanan, penceraian, masalah kesihatan mental dan fizikal, keganasan rumah tangga, taraf sosio-ekonomi yang rendah, tahap pendidikan, agama, kemahiran keibubapaan dan sebagainya. Tingkah laku delinkuen dalam kalangan remaja juga selalu dikaitkan dengan isu perapatan kepada keluarga (McKelvey et al., 2015). Sebagai contoh, Ainsworth et al. (1978) dan Pascuzzo, Moss dan Cyr (2015) mendapati perapatan yang tidak selamat (insecure attachment) dengan ibu bapa pada usia remaja menyebabkan mereka berkecenderungan tinggi mengalami simptom psikopatologi apabila meningkat dewasa lalu terlibat dalam kancah jenayah dan anti-sosial.

Ketidakfungsiaan yang baik juga menyebabkan keluarga gagal mewujudkan persekitaran yang sejahtera kepada remaja. Remaja ditimpa konflik dan tekanan psikologi menyebabkan mereka berisiko terjebak dalam tingkah laku anti-sosial (McWhirter et al., 2013). Akibat kepincangan kefungsian keluarga juga, pendidikan anak-anak turut terabai yang menyebabkan berlaku pula masalah keciciran daripada sistem pendidikan formal iaitu persekolahan. Ini menyebabkan mereka tidak dapat meneruskan kehidupan dalam masyarakat dan negara yang bergerak ke arah industri berteknologi tinggi kerana kurang memiliki kompetensi akademik yang baik. Kemahiran numerasi dan literasi daripada pendidikan akademik amat penting dimiliki oleh remaja bagi membantu membina kecerdasan kognitif dan sosial mereka. Kebanyakan remaja yang berasal dari keluarga yang mengakami kepincangan tidak mencapai tahap kompetensi akademik yang sepatutnya dimiliki menyebabkan mereka hilang arah tuju dan tidak dapat membuat pertimbangan sewajarnya (McWhirter et al., 2013).

Walaupun pelbagai faktor seperti aspek kekeluargaan telah dikaitkan dengan tingkah laku delinkuen dan jenayah, namun begitu, kajian-kajian psikologi, sosiologi dan kriminologi dalam negara kurang memfokuskan aspek-aspek tersebut secara mendalam. Selain itu, dapatan kajian yang diperoleh melalui kajian-kajian luar negara tidak patut digenalisasikan dalam konteks negara Malaysia disebabkan perbezaan faktor budaya, gaya hidup, agama dan geografi (Mohammad Rahim et al., 2016). Faktor budaya Malaysia dan barat khususnya dari aspek kekeluargaan tidak boleh disamakan kerana nilai dan moral yang agak berbeza. Justeru, penting untuk meneliti aspekaspek seperti ini dalam konteks tempatan. Dengan jumlah banduan muda yang dianggap ramai di Malaysia, kajian-kajian sebegini adalah sangat mustahak kerana ia dapat memberi pencerahan kepada ahli akademik, pembuat dasar dan juga masyarakat dalam proses memahami tingkah laku delinkuen dan jenayah dalam kalangan remaja.

Bukan itu sahaja, pemahaman yang mendalam tentang fenomena tingkah laku delinkuen dan jenayah turut menjadi garis dasar untuk menggubal langkah-langkah pencegahan proaktif berkaitan tingkah laku delinkuen. Justeru, kajian kualitatif ini adalah untuk mengenal pasti dan meneroka kefungsiaan kekeluargaan terhadap tingkah laku delinkuen dan jenayah dalam kalangan banduan muda lelaki yang menjalani hukuman di salah sebuah Sekolah Integriti di Malaysia. Kajian ini memilih untuk meneroka aspek kefungsiaan kekeluargaan bagi dijadikan sebagai garis panduan untuk membangunkan modul-modul di sekolah untuk mengelak remaja sekolah dan para pelajar terlibat dalam jenayah dan tingkah laku delinkuen.

\section{Perspektif perundangan}

Melihat daripada aspek perundangan, banduan muda adalah ditakrifkan sebagai mereka yang tergolong di bawah umur 21 tahun (Akta Penjara, 1995). Umur permulaan untuk dianggap sebagai 
banduan muda adalah daripada 16 tahun dan keatas tetapi di bawah umur 21 tahun (seksyen 2 Kanun Tatacara Jenayah). Aspek masalah kekeluargan yang mendorong kepada kesalahan jenayah oleh banduan muda lelaki ini boleh menjadi satu faktor mitigasi atau peringan kepada kesalahan yang dilakukan. Faktor mitigasi atau peringan ini akan diambil kira oleh Mahkamah sewaktu pengadilan kes terbabit dalam memutuskan jenis hukuman yang bersesuaian. Mahkamah adalah lebih prihatin dan berhati-hati dalam hukuman yang dikenakan terhadap banduan muda dan kebarangkalian untuk menjatuhkan hukuman penjara adalah kurang (kes Re Johari bin Ismail, [1956] 22 Malayan Law Journal 56). Hal ini demikian kerana hukuman penjara memberikan kesan psikologi yang mendalam terhadap jiwa banduan muda tersebut selain stigma sosial dalam masyarakat serta menghancurkan keyakinan diri dalam banduan muda tersebut untuk berdepan dengan kewajipan dan tugas kehidupan peribadinya selepas dibebaskan daripada penjara. Penelitian terhadap latar belakang, sejarah, watak, keadaan sekeliling dan rekod lampau seseorang banduan muda yang dizahirkan menerusi laporan akhlak akan dikaji oleh Mahkamah dalam memberikan hukuman yang sewajarnya (kes Tukiran bin Taib v Public Prosecutor [1955] 2 Malayan Law Journal 24).

\section{Metodologi}

\section{Reka bentuk kajian, peserta kajian dan lokasi kajian}

Kajian ini telah menggunakan reka bentuk jenis kualitatif. Penggunaan reka bentuk ini adalah bertujuan untuk mendalami dengan lebih lanjut mengenai pengalaman hidup peserta kajian yang terlibat di dalam jenayah sehingga dimasukkan ke Sekolah Integriti, Jabatan Penjara Malaysia. Hal ini adalah kerana melalui reka bentuk kualitatif ini, penyelidik dapat bersemuka dengan peserta kajian di samping dapat melihat sendiri reaksi yang ditunjukkan oleh mereka dan emosi yang dilahirkan sama ada dari segi verbal mahupun pergerakan badan. Pendekatan ini lebih sesuai dijalankan berbanding pendekatan kuantitatif kerana pendekatan kuantitatif tidak dapat meneroka isu ini dengan lebih mendalam di samping tidak dapat mengawal persekitaran semasa peserta kajian diajukan soalan-soalan yang diberikan.

Peserta kajian terdiri daripada banduan muda lelaki warganegara Malaysia sahaja yang melakukan kesalahan jenayah dan ditempatkan di Sekolah Integriti. Mereka juga terdiri daripada banduan muda lelaki yang masuk atas perintah mahkamah dan dipilih berdasarkan kriteria inklusi yang telah ditetapkan oleh penyelidik. Antara kriteria inklusi yang ditetapkan oleh penyelidik ialah bukan banduan bersiko tinggi, tidak agresif dan bukan dari kalangan tahanan reman. Untuk memastikan penyertaan banduan muda lelaki yang dipilih sebagai peserta kajian adalah secara sukarela dan tiada tekanan daripada pihak penjara mahupun penyelidik, banduan muda lelaki telah diberikan Borang Keizinan Peserta untuk ditandatangani bagi mendapatkan keizinan dan persetujuan mereka dalam menyertai kajian ini. Kajian ini juga telah mendapat kebenaran dari pihak Jabatan Penjara Malaysia.

Oleh kerana kajian yang menggunakan reka bentuk kualitatif tidak memerlukan pengutipan data yang banyak tetapi sebaliknya berusaha untuk memperoleh maklumat berkualiti dengan memberi perhatian kepada sampel yang kecil (Azizah Hamzah, 2010), kajian ini telah memfokuskan kepada 12 orang peserta yang telah memenuhi kriteria yang diperlukan dalam kajian ini. Dapatan kajian juga dikatakan telah mencapai tahap ketepuan dengan temu bual bersama 12 peserta. 


\section{Kaedah pengumpulan data}

Penyelidik telah menggunakan teknik temu bual secara mendalam dengan soalan terbuka. Soalan temu bual yang digunakan di dalam kajian ini adalah hasil daripada perbincangan di antara penyelidik dan pakar-pakar bidang yang disediakan terlebih dahulu sebelum menjalankan pengumpulan data kajian. Soalan yang terdiri daripada soalan terbuka dapat membuatkan peserta kajian terbuka untuk menjawab soalan di samping memudahkan mereka untuk bercerita tanpa terikat dengan soalan-soalan yang diberikan. Sekiranya perlu, penyelidik telah menggunakan teknik probing untuk meneroka isu dengan lebih mendalam (Siti Nurkhairina Mohd Nor, Mohammad Rahim Kamaluddin \& Wan Shahrazad Wan Sulaiman, 2019).

Sebelum penyelidik menjalankan sesuatu temu bual, penyelidik telah membuat persediaan yang terperinci terlebih dahulu di samping mengikut prosedur yang telah ditetapkan. Antara prosedur yang dilakukan oleh penyelidik sebelum menjalankan temu bual ialah penyelidik mencari tempat yang sesuai untuk menjalankan temu bual dan mendapatkan kebenaran untuk menjalankan temu bual daripada pihak yang berkenaan. Setelah mendapatkan kebenaran, penyelidik juga menyediakan Borang Termaklum Peserta dan Borang Keizinan Peserta yang diberikan kepada peserta kajian sebelum menemubual mereka bagi mendapatkan kebenaran dan persetujuan mereka. Setiap peserta diucapkan dengan ucapan ribuan terima kasih dan anggaran masa yang diambil oleh setiap peserta adalah lebih kurang satu hingga dua jam.

\section{Analisis data}

Penyelidik telah menggunakan kaedah analisis tematik untuk mencungkil aspek kefungsiaan kekeluargaan yang menjadi penyumbang tingkah laku delinkuen dalam kalangan banduan muda lelaki. Analisis tematik ialah analisis yang digunakan untuk mengenal pasti tema, konsep dan juga makna. Analisis tematik ini amat fleksibel, mudah dan sesuai bagi penyelidik yang tidak mempunyai pengalaman dalam penyelidikan kualitatif, dan hasil analisis tersebut dapat memberi maklumat kepada masyarakat, ini yang dinyatakan oleh Braun dan Clarke (2006). Proses pertama yang dilakukan oleh penyelidik selepas menjalankan temu bual ialah mencatat kembali perbualan yang dilakukan dalam temu bual yang dijalankan. Kemudian transkrip temu bual dianalisis dengan menggunakan kaedah analisis ini untuk meneroka aspek kefungsiaan kekeluargaan yang menjadi penyebab tingkah laku delinkuen.

\section{Hasil dapatan kajian dan perbincangan}

Melalui dapatan kajian, penyelidik telah mendapati bahawa peserta kajian berasal daripada pelbagai latar belakang yang berbeza. Perkara ini dapat dilihat dengan jelas melalui Jadual 1 dan Jadual 2 yang menunjukkan latar belakang peribadi banduan muda lelaki dan latar belakang kesalahan jenayah mereka. 
Jadual 1. Latar belakang peribadi peserta kajian.

\begin{tabular}{|c|c|c|c|c|c|c|}
\hline $\begin{array}{l}\text { Pesert } \\
\text { a } \\
\end{array}$ & $\begin{array}{l}\text { Umu } \\
\mathbf{r}\end{array}$ & Bangsa & Agama & Pekerjaan Ayah & Pekerjaan Ibu & $\begin{array}{l}\text { Pendidikan } \\
\text { Terakhir }\end{array}$ \\
\hline 1 & 16 & Melayu & Islam & Meninggal & Pembuat kek & Tingkatan 4 \\
\hline 2 & 20 & Cina & Buddha & Berniaga & Tidak bekerja & PMR \\
\hline 3 & 19 & Melayu & Islam & Pesara & Tukang bersih & UPSR \\
\hline 4 & 19 & Melayu & Islam & Pengawal & Tidak bekerja & SPM \\
\hline 5 & 19 & Melayu & Islam & Pemandu & Tidak bekerja & Tingkatan 2 \\
\hline 6 & 19 & Melayu & Islam & Kerani & Tidak bekerja & Kolej vokasional \\
\hline 7 & 19 & Melayu & Islam & Pembantu sekolah & Kerani & SPM \\
\hline 8 & 20 & Melayu & Islam & Pesara tentera & Kerani & SPM \\
\hline 9 & 20 & India & Hindu & Meninggal & $\begin{array}{l}\text { Bekerja } \\
\text { Singapura }\end{array}$ & SPM \\
\hline 10 & 20 & Melayu & Islam & Meninggal & Pemandu teksi & UPSR \\
\hline 11 & 21 & Bajau & Islam & Pegawai & Tidak bekerja & Tingkatan 2 \\
\hline 12 & 20 & Melayu & Islam & Penyelia kilang & Tukang cuci & UPSR \\
\hline
\end{tabular}

Jadual 2. Latar belakang kesalahan jenayah peserta kajian.

\begin{tabular}{llllll}
\hline Peserta & $\begin{array}{l}\text { Umur } \\
\text { Terlibat } \\
\text { Kesalah } \\
\text { an }\end{array}$ & $\begin{array}{l}\text { Tahun } \\
\text { Kemasukan }\end{array}$ & Kesalahan & Tempoh Hukuman & $\begin{array}{l}\text { Kali Ke Berapa } \\
\text { Memasuki Penjara }\end{array}$ \\
\hline 1 & 16 & $04 / 2016$ & Samun bersenjata & 8 bulan & 1 \\
2 & 16 & $04 / 2016$ & 302 & Tiada tarikh & 1 \\
& & & & (reman 4 tahun) \\
3 & 9 & 2009 & Samun bersenjata & 3 tahun & 2 \\
4 & 16 & $02 / 2016$ & Dadah & 1 tahun 2 bulan & 1 \\
5 & 16 & $11 / 2015$ & Menyembunyikan & 2 tahun & 1 \\
& & & kelahiran & 2 tahun & 1 \\
6 & 18 & $01 / 2016$ & Pecah rumah & 3 tahun & 1 \\
7 & 15 & $03 / 2016$ & Samun & 1 \\
8 & 16 & $01 / 2015$ & Dadah berbahaya & 2 tahun 6 bulan & 1 \\
9 & 17 & $04 / 2015$ & 302 & 12 tahun & 1 \\
10 & 17 & $05 / 2016$ & Rogol & 7 tahun & 1 \\
11 & 19 & $01 / 2015$ & Rogol & 9 tahun & 2 \\
12 & 13 & $06 / 2015$ & Rogol tahun 6 bulan & 1 \\
\hline
\end{tabular}

\section{Kefungsiaan kekeluargaan}

Aspek kefungsiaan kekeluargaan menerangkan mengenai bagaimana peserta kajian ini boleh terlibat dengan kesalahan jenayah sehingga menyebabkan mereka dimasukkan ke Sekolah Integriti. Penyelidik mendapati munculnya beberapa sub-tema kecil di bawah aspek kefungsiaan kekeluargaan di mana kebanyakan peserta yang terlibat dengan tingkah laku delinkuen ini disebabkan kekurangan kasih sayang, keluarga bermasalah, dendam terhadap ahli keluarga dan juga terdapat ahli keluarga yang terlibat dengan jenayah; yang menyebabkan banduan muda ini tersasar kepada kesalahan jenayah dan tingkah laku delinkuen. 
a. Kekurangan kasih sayang

Kekurangan kasih sayang merupakan antara faktor yang menyumbang kepada aspek kefungsiaan kekeluargaan kepada tingkah laku delinkuen dalam kalangan banduan muda di Sekolah Integriti. Daripada 12 peserta dalam kajian ini didapati majoriti banduan menceritakan tentang isu kekurangan kasih sayang dari ahli keluarga khususnya daripada ibu bapa. Kasih sayang antara ahli keluarga amat penting terutama bagi para remaja yang sedang mengalami transisi daripada usia kanak- kanak kepada kehidupan remaja yang dikatakan penuh cabaran. Hal ini kerana pada usia remaja, mereka amat memerlukan perhatian daripada ahli keluarga terutama ibu bapa walaupun kebanyakan mereka lebih mementingkan rakan sebaya di segenap hal hidup mereka.

Faktor kurangnya kasih sayang dan perhatian daripada ahli keluarga telah menjadikan kebanyakan banduan muda lelaki ini merasakan bahawa keluarga tidak menyayangi mereka malah mungkin kasih sayang yang dicurahkan tidak memadai dan mencukupi sehinggakan mereka tidak dapat merasai kasih sayang yang diberikan oleh ahli keluarga. Oleh sebab itu juga para banduan muda lelaki ini lebih memilih kawan untuk berkongsi segenap hal kehidupan kerana mereka merasakan kawan dan rakan sebaya memberikan sepenuh perhatian kepada mereka berbanding ahli keluarga. Sebagai contohnya, peserta keenam menyatakan bahawa dirinya dipinggirkan kerana dirinya merupakan anak angkat sahaja dalam keluarga tersebut. "Hubungan saya dengan ahli keluarga biasa sahaja sebab saya anak angkat dan ibu lebih sayangkan kakak (anak kandung sendiri) berbanding saya. Saya sering berasa kecewa kerana kurang kasih sayang daripada mereka" (Peserta keenam).

Perkara yang sama juga diceritakan oleh Peserta yang ke-10. Menurut Peserta yang ke-10, "Saya tidak dikisah dan disayangi oleh sesiapa jua dalam ahli keluarga. Malahan, hari jadi saya pun tidak pernah disambut atau diucap oleh mereka. Hubungan saya dengan ahli keluarga saya boleh dikatakan macam orang ketiga dan renggang (Peserta ke-10). Hubungan yang renggang antara ibu bapa dengan anak-anak menjadi faktor penyumbang kepada kes juvana. Menurut Fauziah Ibrahim et al. (2020), ikatan kasih sayang yang kuat yang terjalin antara individu membuatkan individu itu akan berasa dirinya dihargai. Ini juga boleh dikaitkan dalam konteks keluarga dimana anak perlu merasakan diri mereka dihargai oleh ibu bapa agar hubungan yang baik dapat terjalin. Apabila kurangnya kasih sayang diberikan oleh ahli keluarga, ini secara lansgung menyebabkan para remaja berasa terasing dari keluarga dan memberi ruang untuk mereka mencari alternatif lain termasuk tingkah laku delinkuen. Hal ini banyak disokong dalam kajian-kajian lepas antaranya Zainudin Sharif dan Norazmah Mohamad Roslan (2011) yang menyimpulkan bahawa ibu bapa yang tidak mempunyai banyak masa di rumah menyebabkan komunikasi yang kurang antara ibu bapa dengan anak-anak hingga mereka bertindak mencari medium lain seperti menghabiskan banyak masa dengan rakan-rakan sebaya yang akhirnya boleh mendorong mereka untuk terlibat dengan perkara-perkara yang membahayakan dan terjebak dengan gejala sosial.

\section{b. Keluarga bermasalah}

Faktor kedua yang menyumbang kepada aspek kekeluargaan ialah keluarga bermasalah. Hal ini kerana daripada 12 peserta dalam kajian, majoriti daripada mereka menyatakan keluarga yang bermasalah sebagai antara pemangkin terjadinya jenayah dalam kalangan banduan muda lelaki. Faktor keluarga bermasalah seperti perceraian antara ibu dan bapa, bapa kaki pukul, tidak bertanggung jawab dan sebagainya telah menjadi salah satu penyebab para banduan muda lelaki 
ini melakukan jenayah. Hal ini dapat dilihat, sebagai contohnya apabila peserta kedua menyatakan bahawa sering berlaku pergaduhan antara kedua ibu bapanya kerana ayahnya mempunyai penyakit mental. Berikut merupakan contoh temu bual bagi menerangkan kenyataan di atas. "Semasa saya kecil, baba (ayah) dengan mami (ibu) suka bergaduh, baba ada penyakit sakit jiwa. Baba selalu ambil pisau dan letak dekat mami dan baba selalu masuk hospital sakit jiwa. Baba hanya akan kembali normal kalau ambil ubat. Saya sudah biasa tengok baba dan mami bergaduh sehingga menjadi normal bagi saya" (Peserta kedua). Selain itu, kesibukan ibu bapa mencari nafkah ditambah pula dengan hubungan yang tidak akrab antara adik beradik telah menjadikan banduan muda ini memilih melakukan jenayah. Hal ini dapat dilihat melalui temu bual dengan peserta ketujuh. "Keluarga tidak mengambil berat, ayah dengan ibu saya sibuk dan semua ahli keluarga tidak suka kepada saya sebab saya jahat. Saya tidak berasa rapat dengan mereka sebab mereka sangat sibuk dan tidak kisah tentang masa bersama saya. Ayah pula selalu pukul saya dan ibu bapa saya sudah bercerai semasa saya umur 13 tahun” (Peserta ketujuh).

Faktor keluarga bermasalah ditambah lagi melalui kisah yang diceritakan oleh peserta ke11. Banduan muda lelaki ini telah melaporkan bahawa faktor dilahirkan di dalam keluarga susah dan perceraian antara kedua ibu bapa telah menjadikan dirinya sekarang. Ini dapat dilihat melalui perbualan bersama banduan muda ini. "Saya dilahirkan dalam keluarga yang sangat susah dan miskin. Saya tinggal dengan ibu setelah ibu dan ayah bercerai dan saya tidak berjumpa ayah saya dari umur 3 tahun sampai sekarang" (Peserta ke-11). Begitu juga dengan peserta ke-12 turut memberi respon di mana banduan muda ini melaporkan faktor ayahnya yang curang telah menambahkan kebenciannya terhadap ayahnya. Hal ini ditambah pula dengan sejarah abangnya yang pernah menikam ayahnya sendiri telah menjadikan banduan muda ini tidak segan silu untuk melakukan jenayah. "Keluarga saya bermasalah, ayah saya ada perempuan lain dan abang saya pernah tikam ayah. Kalau gaduh di rumah itu adalah perkara biasa” (Peserta ke-12).

Hasil dapatan kajian ini dapat dibuktikan dengan kajian yang dijalankan oleh Mohd Taib Dora (2004) iaitu masalah kesalahan jenayah dan tingkah laku delinkuen ini seringkali meningkat dari tahun ke tahun dan faktor yang menyumbang kepada masalah tersebut terus meningkat adalah berpunca daripada pelbagai faktor risiko termasuk kurangnya perhatian dari ibu bapa terhadap pergaulan anak-anak mereka serta pengabaian daripada keluarga. Latar belakang keluarga yang berpecah belah dikenal pasti dalam sorotan karya (Hoffmann \& Dufur, 2018; Hirshi, 2017) dalam menyediakan persekitaran yang tidak sesuai atau mencukupi untuk pertumbuhan sihat remaja. Faktor keluarga bermasalah ini mengundang remaja kepada keterlibatan dalam kesalahan jenayah. Ini terbukti dalam kajian ini bahawa isu keluarga yang bermasalah sebagai salah satu faktor risiko yang penting kepada remaja terlibat dalam kancah jenayah.

\section{c. Dendam terhadap ahli keluarga}

Perasaan dendam terhadap ahli keluarga merupakan faktor yang ketiga menyumbang kepada aspek kekeluargaan yang telah menjadikan para banduan ini melakukan jenayah. Hal ini berikutan daripada 12 peserta kajian, didapati majoriti daripada peserta menceritakan dendam terhadap ahli keluarga. Perasaan dendam yang disimpan sekian lama terhadap ahli keluarga telah menjadikan banduan muda ini nekad untuk melakukan jenayah. Ini dapat dilihat pada peserta pertama kajian. Peserta ini mempunyai dendam yang mendalam terhadap ayahnya kerana bertindak kasar terhadap ibunya. "Saya ada simpan rasa dendam dengan ayah dan pernah pukul ayah dengan kayu besbol sebab ayah pijak mak. Saya juga pernah ada perasaan untuk bunuh ayah dengan menyimpan 
pisau bawah katil. Saya juga pernah cuba untuk membunuh ayah tapi tak jadi kerana ibu saya telah melihat pisau itu" (Peserta pertama).

Selain itu, peserta ketiga dan keempat juga menyimpan dendam terhadap abangnya kerana telah memberitahu kepada keluarga tentang aktiviti yang dilakukan olehnya. Sebagai contohnya, peserta keempat memberitahu "Saya ada perasaan dendam dengan abang sulung dan pernah cuba untuk membunuh abang sulung saya. Ini adalah disebabkan oleh abang sulung yang memberitahu kepada ahli keluarga tentang kegiatan yang saya buat ketika berumur 15 tahun" (Peserta keempat). Peserta ke-10 pula mempunyai dendam terhadap seluruh ahli keluarga tanpa sebab yang kukuh. Ini dapat dilihat melalui responnya. "Saya ada menyimpan perasaan dendam dengan abang kandung dan keluarga kandung. Saya pun tak tahu mengapa tetapi saya berasa tidak puas hati terhadap mereka. Saya berasa tidak puas hati dengan mereka mungkin banyak kenangan pahit" (Peserta ke-10). Manakala peserta ke-11pula berdendam dengan ayah kandungnya sendiri kerana ayahnya telah mengabaikan tanggung jawab kepada keluarga dengan membiarkan mereka sekeluarga hidup dalam keadaan yang susah. "Saya berdendam dengan ayah sebab tidak pernah datang jumpa kami adik-beradik dan biarkan kami hidup susah. Disebabkan oleh ayah saya, kami telah hidup miskin. Saya benci dia” (Peserta ke-11).

Dapatan kajian ini adalah sama dengan dapatan Arieff Salleh Rosman dan Wardah Mokhtar (2006) yang menjelaskan perlakuan remaja digambarkan sebagai perlakuan emosi. Menurut Azizi Yahaya dan Rosnah Buang (2007), fenomena ini mungkin berlaku disebabkan remaja yang terlibat ingin meluahkan perasaan tidak puas hati, ingin membalas dendam dan sebagainya lalu terlibat dalam jenayah.

\section{d. Keterlibatan ahli keluarga dalam jenayah}

Faktor ahli keluarga terlibat dengan jenayah merupakan antara faktor yang menyumbang kepada perlakuan jenayah yang telah dilakukan oleh banduan muda lelaki. Ini dapat dilihat daripada reaksi setiap peserta kajian apabila diajukan soalan ini. Kebanyakan daripada reaksi yang ditunjukkan, dapat dilihat bahawa ahli keluarga mereka mempunyai rekod jenayah sehingga para banduan muda lelaki ini terjebak di dalam kancah jenayah. Contohnya, peserta pertama memberi reaksi bahawa rekod ayahnya yang pernah menjual dadah telah menjadikan ayahnya dimasukkan ke penjara. Selain itu, peserta ketiga turut mempunyai ahli keluarga yang mempunyai rekod jenayah. "Adik saya terlibat dengan dadah dan abang sulung terlibat dengan langganan perempuan dan merupakan kaki minum. Agak kerap juga mereka masuk keluar lokap dan pusat serenti" (Peserta ketiga).

Peserta keempat dan peserta kelapan turut memberitahu bahawa abang sulung mereka pernah mempunyai rekod jenayah penglibatan dengan dadah. Berbeza dengan peserta kesembilan, peserta ini mempunyai saudara yang mempunyai rekod jenayah dan dikenakan hukuman penjara di bawah seksyen 302. "Saudara sebelah ayah yang dijatuhi 302 (hukuman bagi kesalahan membunuh dengan niat) atas kesalahan bunuh macam saya juga. Beliau rapat juga dengan saya" (Peserta kesembilan). Keluarga yang gagal berfungsi dengan baik akibat keluarga bermasalah (problem families) dan masalah keluarga (family problems) membawa kepada isu-isu yang berkaitan seperti keluarga terlibat penyalahgunaan bahan dan perlakuan jenayah. Keadaan ini menyebabkan keluarga gagal mewujudkan persekitaran yang sejahtera kepada remaja. Remaja ditimpa konflik dan tekanan psikologi menyebabkan mereka berisiko terjebak dalam tingkah laku anti-sosial (McWhirter et al., 2013). 
Berdasarkan Teori Pembezaan Asosiasi atau Differential Association Theory (Sutherland, 1939) tingkah laku jenayah dan perilaku yang melanggar norma adalah dipelajari daripada individu atau kumpulan yang terdekat dan rapat seperti ahli keluarga. Menurut teori ini, individu atau kumpulan terdekat ini akan mengajar tentang motif, rasional, sikap dan teknik untuk melakukan tingkah laku antisosial tersebut. Dalam konteks perbincangan ini, teori ini boleh diaplikasikan dalam menjelaskan keterlibatan ahli keluarga dalam jenayah sebagai faktor kuat yang mempengaruhi tingkah laku delinkuen dalam kalangan banduan muda di Malaysia.

Elemen-elemen seperti sikap permisif ibu bapa terhadap kawalan disiplin anak-anak, kepimpinan autokratik, hubungan di antara anak dan ibu bapa yang terganggu, layanan yang kasar, contoh idola yang negatif serta keluarga yang berpecah belah, akan menyebabkan anak-anak mengalami tekanan dan kecelaruan emosi yang seterusnya akan melahirkan pelbagai tingkah laku tidak bermoral. Keadaan berterusan sebegini menjadikan remaja akan mencari jalan mudah untuk melupakan masalah tekanan tersebut dan mengambil keputusan untuk terlibat dalam jenayah termasuk penagihan dadah. Kajian juga mendapati kefungsiaan kekeluargaan adalah aspek yang penting dalam membentuk akhlak remaja yang sihat agar terhindar dari kancah jenayah. Perkembangan positif remaja penting dan perlu dititikberatkan bagi memastikan perkembangan remaja yang mampan supaya tidak mudah terjebak dalam kancah jenayah (Fatin Adha Murad, Mohammad Rahim Kamaluddin \& Norruzeyati Che Mohd Nasir, 2020).

\section{Limitasi dan cadangan kajian}

Limitasi kajian ini ialah kajian ini tidak boleh digeneralisasikan kepada keseluruhan remaja yang terlibat dengan kesalahan jenayah dan tingkah laku delinkuen. Hal ini adalah kerana reka bentuk kajian adalah berbentuk kualitatif dan juga peserta kajian ini hanya terdiri daripada 12 orang peserta sahaja. Walaupun peserta kajian ini adalah 12 orang, namun dapatan kajian yang diperoleh secara temu bual dan pemerhatian secara langsung ini sudah dapat memberikan maklumat yang terperinci kepada penyelidik di samping memperoleh maklumat mengenai pengalaman dan emosi mereka dengan sangat mendalam dari sudut kefungsiaan kekeluargaan. Cadangan bagi kajian yang akan datang ialah menggunakan saiz sampel yang lebih besar agar lebih banyak input atau subtema dapat diperoleh dengan metodologi perbandingan kajian kes. Peserta kajian ini adalah sedikit iaitu hanya 12 orang dan kebanyakannya ialah peserta Melayu. Diharapkan agar penyelidik yang akan datang yang berminat untuk mengkaji perkara ini akan menggunakan peserta yang lebih ramai dan menambahkan lagi banduan muda dari pelbagai etnik untuk memastikan ketepatan dan kebolehpercayaan kajian tersebut. Selain itu, populasi yang khusus juga dicadangkan untuk kajiankajian yang akan datang. Jika dilihat dalam profil jenayah banduan muda, kesemua peserta di atas telah melakukan jenayah yang berbeza. Dapatan kajian akan menjadi lebih kukuh sekiranya kajian akan datang memfokuskan banduan muda yang melakukan kesalahan yang sama agar latar belakang kefungsiaan kekeluargaan dapat diteroka secara mikro. Cadangan ini adalah bertujuan untuk memberi panduan kepada penyelidik yang akan datang bagi memantapkan lagi kajian yang akan datang terutamanya yang berkaitan dengan penglibatan remaja dalam jenayah dan delinkuensi. Penyelidik berharap agar cadangan ini dapat diberi perhatian untuk kajian yang akan dilakukan pada masa yang akan datang. 


\section{Kesimpulan}

Secara keseluruhannya, kajian ini telah mencapai objektifnya untuk meneroka aspek kefungsiaan kekeluargaan dalam kalangan banduan muda lelaki. Hasil dapatan kajian tentang aspek kefungsiaan kekeluargaan telah menunjukkan bahawa mereka kekurangan kasih sayang daripada keluarga mereka, datang daripada keluarga bermasalah, menyimpan perasaan dendam terhadap ahli keluarga dan mempunyai ahli keluarga yang pernah terlibat dalam jenayah; menjadi faktor risiko yang utama dalam keterlibatan jenayah. Adalah diharapkan agar dapatan kajian ini memberi input signifikan kepada institusi kekeluargaan dalam membesarkan anak-anak mereka agar terhindar dari kancah jenayah. Dapatan juga bermanfaat dalam memberikan aspek yang perlu diberi fokus dalam modul-modul kemahiran keibubapaan yang boleh dibangunkan sama ada oleh agensi kerajaan atau Pertubuhan Bukan Kerajaan.

\section{Rujukan}

Akta Kanak-Kanak 2001, Akta 611. Malaysia.

Akta Penjara 1995. Malaysia.

Ainsworth, M.S., Blehar, M.C., Waters, E., \& Wall, S. (1978). Patterns of attachment: A psychological study of the strange situation. Oxford, England: Lawrence Erlbaum.

Arieff Salleh Rosman, \& Wardah Mokhtar. (2006). Membentuk jati diri remaja. Bentong: PTS Professional Publishing Sdn. Bhd.

Azizah Hamzah. (2010). Kaedah kualitatif dalam penyelidikan sosiobudaya. Jurnal Pengajian Media Malaysia, 6(1), 1-10.

Azizi Yahaya, \& Rosnah Buang. (2007). Punca berlakunya masalah gejala gengsterisme di kalangan remaja di beberapa buah sekolah menengah di empat buah negeri. Skudai: Penerbit Universiti Teknologi Malaysia.

Braun, V. \& Clarke, V. (2006). Using thematic analysis in Psychology. Qualitative Research in Psychology, 3, 77-101.

Fatin Adha Murad, Mohammad Rahim Kamaluddin, \& Norruzeyati Che Mohd Nasir. (2020). Hubungan Kesukaran Meregulasi Emosi dan Tingkah Laku Delinkuen dalam Kalangan Remaja: Perapatan kepada Komuniti sebagai Perantara. Akademika, 90(2), 3-16.

Fauziah Ibrahim, Wan Shahrazad Wan Sulaiman, Ezarina Zakaria, \& Mohammad Rahim Kamaluddin. (2020). Pengintegrasian sosial: Sejauhmana hubungannya dengan kesihatan diri, keagamaan dan jaminan pekerjaan dalam kalangan orang kena pengawasan. Geografia-Malaysian Journal of Society and Space, 16(3), 135-146.

Hirschi, T. (2017). Causes of delinquency. New York: Routledge.

Hoffmann, J.P. \& Dufur, M.J. (2018). Family social capital, family social bonds, and juvenile delinquency. American Behavioral Scientist, 62(11), 1525-154.

Jabatan Penjara Malaysia. (2014). Program Pembangunan Insan. Bandar Baru Bangi: United Mind.

McKelvey, L.M., Conners-Burrow, N.A., Mesman, G.R., Pemberton, J.R., \& Casey, P.H. (2015). Promoting adolescent behavioural adjustment in violent neighbourhoods: Supportive families can make a difference! Journal of Clinical Chile \& Adolescent Psychology, 44(1), 157-168. 
McWhirter, J., McWhirter, B., McWhirter, E. \& McWhirter, R. (2013). At-risk youth: A comprehensive response for counselors, teachers, psychologists, and human professional. Belmont CA: Brooks/Cole.

Mohammad Rahim Kamaluddin, Azizah Othman, Khaidzir Ismail, \& Geshina Ayu Mat Saat. (2016). Aggression Profiles of Incarcerated Malaysian Male Murderers. Akademika, 86(2), 137-147.

Mohd Taib Dora. (2004). Isu dan faktor penderaan kanak-kanak dan juvana di Negeri Johor Darul Takzim. Skudai: Penerbit Universiti Teknologi Malaysia.

Pascuzzo, K., Moss, E., \& Cyr, C. (2015). Attachment and emotion regulation strategies in predicting adult psychopathology. Sage Open, 5(3).

Pereire, M.B., \& Maia, A.D.C. (2017). Juvenile delinquency, crime and social marginalization: social and political implications. Emerald Publishing Ltd: UK.

Regoli, R.M., Hewitt, J.D., \& Delisi, M. (2008). Delinquency in Society: Youth Crime in the 21st Century. 7th edition. Boston: McGraw Hill.

Siti Nurkhairina Mohd Nor, Mohammad Rahim Kamaluddin, \& Wan Shahrazad Wan Sulaiman. (2019). Profil Jenayah Banduan Wanita di Malaysia: Satu Kajian Kualitatif. Akademika, 89(2), 43-56.

Sutherland, E.H. (1939). Principles of Criminology. Philadelphia: Lippincott.

Zainudin Sharif, \& Norazmah Mohamad Roslan. (2011). Faktor-faktor yang mempengaruhi remaja terlibat dalam masalah sosial di Sekolah Tunas Bakti, Sungai Lereh, Melaka. Journal of Education Psychology \& Counseling, 1, 115-140. 